Jurnal As-Salam, 2(2) Mei - Agustus 2018
(Print ISSN 2528-1402, Online ISSN 2549-5593)

\title{
PERUBAHAN BAHASA DAN BUDAYA JAWA DI YOGYAKARTA PADA ERA GLOBALISASI
}

\author{
Sungkawati Kardi Wahyuningsih ${ }^{1}$, Andika Hariyanto Surbakti ${ }^{2}$ \\ ${ }^{1}$ STAIN Gajah Putih Takengon Aceh Tengah, Aceh \\ Email: kardisungkawati@gmail.com \\ ${ }^{2}$ STAIN Gajah Putih Takengon Aceh Tengah, Aceh \\ Email: andikahariyanto_surbakti@yahoo.com
}

\begin{abstract}
Abstrak. Tulisan ini mengulas tentang perubahan bahasa dan kebudayaan Jawa di Yogyakarta. Perubahan bahasa Jawa meliputi semua aspek kebahasaan, baik fonologi (bunyi), morfologi (bentuk), sintaksis (kalimat), kosakata dan semantik (makna). Faktor-faktor yang menyebabkan terjadinya perubahan bahasa adalah: perkembangan dalam ilmu dan teknologi, perkembangan sosial dan budaya, perbedaan bidang pemakaian, adanya asosiasi dan pertukaran tanggapan indera. Bahasa bukan hanya menentukan corak budaya, melainkan juga menentukan cara dan jalan pikiran manusia, sehingga mempengaruhi tingkah lakunya. Perbedaan-perbedaan budaya dan jalan pikiran manusia bersumber pada perbedaan bahasa. Karena bahasa dan budaya merupakan satu-kesatuan yang tidak dapat dipisahkan, maka ketika suatu bahasa mengalami pergeseran hal serupa juga terjadi pada budayanya. Budaya Jawa di Yogyakarta telah bergeser dalam penggunaanya dalam kehidupan sehari-hari.
\end{abstract}

Kata kunci: perubahan bahasa, jawa, Yogyakarta.

\section{Pendahuluan}

Bahasa mempunyai peran yang sangat besar bagi kehihupan manusia. Selain sebagai alat komunikasi, bahasa juga merupakan alat pemersatu bagi sebuah negara seperti indonesia. Selain itu, bahasa merupakan cermin budaya dari penuturnya. Bahasa dan kebudayaan tidak dapat dipisahkan ... Bahasa dan kebudayaan kita ... mencerminkan jati diri kita, dari mana kita berasal dan kemana kita akan pergi (Task Force on Aboriginal Language and Cultures dalam Spolsky dan Hult, 2008: 298).

Ketika kita kehilangan sebuah bahasa, maka kita juga kehilangan kebudayaan, kekayaan intelektual dan kesenian (The Economist, dalam Spolsky dan Hult, 2008: 298). Indonesia merupakan negara yang memiliki wilayah yang luas serta keanekaragaman budaya dan bahasa. Keberadaan bahasa daerah yang begitu banyak akan punah ketika bahasa tersebut tidak memiliki penutur.

Bahasa dan kebudayaan Jawa di Yogyakarta tidak luput dari ancaman kepunahan. Ancaman tersebut dapat kita temui dalam kehidupan sehari-hari, seperti semakin jarang penduduk Yogyakarta yang berkomunikasi dengan bahasa Jawa terutama di wilayah perkotaan karena pendatang lebih banyak bertempat tinggal di perkotaan. Seiring perpindahan penduduk luar ke Yogyakarta, mereka juga membawa kebudayaan asal ke Yogyakarta. Hal itu yang menyebabkan perubahan bahasa dan budaya jawa di Yogyakarta. 
Chaer dan Agustina (2004: 136) menjelaskan bahwa perubahan bahasa lazim diartikan sebagai adanya perubahan kaidah, baik kaidah yang direvisi, kaidahnya menghilang atau munculnya kaidah baru; dan semua itu dapat terjadi pada semua tataran linguistik: fonologi, morfologi, sintaksis, semantik, maupun leksikon.

Semua hasil proses perkembangan bahasa, baik penambahan, pengurangan, maupun penggantian dalam bidang apa saja pada bahasa termasuk bunyi, bentuk dan makna dapat ditandai sebagai perubahan bahasa. Pada dasarnya ada dua macam perubahan dalam bahasa, yakni perubahan yang terjadi "di dalam" bahasa itu sendiri, yang disebut perubahan internal, dan perubahan "oleh pengaruh" bahasa lain, yang disebut perubahan eksternal. Oleh karena unsur bahasa terkecil yang dapat berdiri sendiri adalah kata, maka yang dimaksud dengan perubahan internal adalah perubahan yang terdapat pada kata-kata asli bahasa tersebut.

Chaer (1994:310) menyatakan bahwa secara sinkronis makna sebuah kata atau leksem tidak akan berubah, tetapi secara diakronis ada kemungkinan dapat berubah. Maksudnya, dalam masa yang relatif singkat, makna sebuah kata akan tetap sama, tidak berubah; tetapi dalam waktu yang relatif lama ada kemungkinan makna sebuah kata akan berubah, dan hal ini tidak berlaku untuk semua kosakata yang terdapat dalam sebuah bahasa, melainkan hanya terjadi pada sejumlah kata saja, yang disebabkan oleh berbagai faktor.

Faktor-faktor yang menyebabkan terjadinya perubahan makna dan jenis-jenis perubahan makna adalah: (a). Perkembangan dalam ilmu dan teknologi; (b). Perkembangan sosial dan budaya; (c). Perbedaan bidang pemakaian; (d). Adanya asosiasi; dan (e). Pertukaran tanggapan indera.

Holmes (1995) menjelaskan tentang bagaimana perubahan suatu bahasa dapat terjadi; Pertama, dari satu kelompok ke kelompok lain. Para ahli bahasa menjelaskan perubahan bahasa dari suatu kelompok. Beberapa perubahan terjadi dengan cara yang berbeda-beda. Faktor-faktor sosial seperti umur, status, gender, dan lingkungan mempengaruhi cara-cara perubahan bahasa. Perubahan bahasa terjadi pada suatu kelompok tutur melalui orang-orang yang mempunyai interaksi dengan kelompok tutur lain. Kedua, dari satu gaya bahasa ke gaya bahasa lain (dari bahasa formal ke bahasa kasual). Dalam suatu masyarakat tutur, perubahan bahasa terjasi pada gaya bahasa yaitu dari bahasa formal ke bahasa kasual, dan pada waktu yang bersamaan perubahan tersebut terjasi pada satu individu kepada kelompok sosial lain, atau dari satu kelompok sosial ke kelompok sosial lain. Ketiga, dari satu kata ke kata yang lain (lexical diffusion). Perubahan ini merupakan perubahan bunyi suatu suku kata karena pengaruh bunyi suku kata yang lain. Perubahan ini biasanya terjadi pada penutur muda. Misalnya, pengucapan kata beer dan bear, fear dan fair, dan lain sebagainya.

Berdasarkan hasil analisis tersebut dapat disimpulkan bahwa semua hasil proses perkembangan bahasa, baik penambahan, pengurangan, maupun penggantian dalam bidang apa saja pada bahasa termasuk bunyi, bentuk, makna dapat ditandai sebagai perubahan bahasa. Pada dasarnya perubahan ada dua macam, yakni perubahan internal (perubahan yang terjadi di dalam bahasa itu sendiri) dan perubahan eksternal (perubahan karena pengaruh dari bahasa lain). Globalisasi merupakan sebuah istilah yang memiliki hubungan dengan peningkatan keterkaitan dan ketergantungan antar bangsa dan antar manusia di seluruh dunia melalu perdagangan, investasi, perjalanan, budaya populer dan bentuk-bentuk interaksi lain sehingga batas-batas negara menjadi semakin sempit. Untuk 
mendukung keterlangsungan suatu hubungan, maka manusia wajib menguasai lingua frangka yang menjadi penghubung antar negara.

Saat ini, bahasa Inggris menjadi bahasa komunikasi masyarakat di seluruh dunia, termasuk di Indonesia, meskipun bukan bahasa sehari-hari. Seluruh sekolah di Indonesia memberikan pembelajaran bahasa Inggris kepada setiap siswanya agar menjdai bekal dalam kehidupan mendatang. Tidak dapat dipungkiri bahwa globalisasi telah membentuk masyarakat Indonesia, khususnya Yogyakarta, menjadi masyarakat multilingual.

Weinrich mendefinisikan multilingual sebagai masyarakat yang menggunakan tiga bahasa atau lebih secara bergantian. Bahasa dalam penggunaanya tidak terbatas. Bahkan bahasa itu bukan sekedar alat komunikasi saja, melainkan juga digunakan sebagai alat untuk menunjukkan identitas kelompok (Chaer, 2004:91).

Sorensen dalam Pride dan Holmes (1972: 78) mendefinisikan seorang multilingual adalah orang yang menguasai tiga, empat atau lebih suatu bahasa dengan baik. Orang tersebut mampu berkomunikasi dengan bahasa-bahasa yang dia kuasai. Multilingual terjadi karena adanya perpindahan. Multilingual adalah masyarakat yang mempunyai beberapa bahasa. Masyarakat yang demikian terjadi karena beberapa etnik ikut membentuk masyrakat sehingga dari segi etnik bisa dikatakan sebagai masyarakat majemuk (plural society). (Sumarsono dan Paina Partana, 2002: 76).

Sapir dalam Wardhaugh (2000: 216) mengemukakan bahwa bahasa bukan hanya menentukan corak budaya, melainkan juga menentukan cara dan jalan pikiran manusia, sehingga mempengaruhi tingkah lakunya. Dengan kata lain, suatu daerah yang berbeda bahasanya dari daerah lain akan mempunyai corak budaya dan jalan pikiran yang berbeda pula. Jadi, perbedaan-perbedaan budaya dan jalan pikiran manusia bersumber pada perbedaan bahasa.

Nababan dalam Chaer dan Agustina (2004: 164) menyatakan bahwa kebudayaan adalah sistem aturan-aturan komunikasi dan interaksi yang memungkinkan suatu masyarakat terjadi, terpelihara dan dilestarikan. Dengan kata lain, kebudayaan adalah segala hal yang menyangkut kehidupan manusia, termasuk aturan atau hukum yang berlaku dalam masyarakat, hasil-hasil yang dibuat manusia, kebiasaan, dan tradisi yang biasa dilakukan, termasuk juga alat interaksi atau komunikasi yang digunakan, yakni bahasa dan alat-alat komunikasi nonverbal lainnya.

Kebudayaan dalam arti yang luas dapat diterjemakan sebagai berikut: Semua hasil cipta, rasa, karsa, dan karya manusia, yang dapat digunakan untuk memudahkan hidup. Dengan demikian maka tradisi, adat istiadat/prilaku, akhlaq/budi pekerti, tempat tinggal, pergaulan, dan bahasa, semuanya dapat dikatakan kebudayaan atau hasil budaya.

Kroeber dan Kluckhohn (dalam Nababan, 1991: 49) mengelompokkan kebudayaan menjadi enam, yaitu:

1. deskriptif (menekankan unsur-unsur kebudayaan)

2. historis (menekankan bahwa kebudayaan itu diwarisi secara kemasyarakatan)

3. normatif (menekankan hakikat kebudayaan sebagai aturan hidup dan tingkah laku)

4. psikologis (menekankan kegunaan kebudayaan dalam penyesuaian diri pada lingkungan)

5. struktural (menekankan sifat kebudayaan sebagai suatu sistem yang berpola dan teratur)

6. genetis (menekankan terjadinya kebudayaan sebagai haasil karya manusia) 
Bahasa Jawa merupakan bahasa yang digunakan sebagai bahasa pergaulan seharihari di daerah Jawa, khususnya Jawa Tengah dan Yogyakarta. Hal ini tidak mengherankan karena kejayaan kehidupan kraton dimasa lampau banyak terdapat di daerah Jawa Tengah dibanding di daerah Jawa yang lain. Kehidupan dan kejayaan kerajaan Mataram Islam di Jawa, misalnya Kerajaan Surakarta Hadiningrat, dan juga Kerajaan Ngayogyakarta Hadiningrat, ikut memberikan andil mengapa bahasa Jawa banyak diketahui dan digunakan sebagai bahasa sehari-hari dalam pergaulan keluarga, maupun dalam pergaulan di masyarakat Jawa. Bahasa Jawa merupakan salah satu hasil Kebudayaan Jawa.

Sabar Narimo (2009) menjelaskan bahwa masyarakat Jawa merupakan suatu keasatuan masyarakat yang dikait oleh norma-norma hidup, tradisi maupun agama. Ciriciri religius, non-doktrin, toleran, akomodatif dan optimistik adalah ciri utama yang menonjol pada kebudayaan Jawa. Macam-macam keselarasan antara gaya hidup dan kenyataan fundamental yang dirumuskan dalam simbol-simbol sakral sangat bervariasi dari satu kebudayaan ke kebudayaan lain yang kemudian membentuk komunitas khas Jawa yang istilah masyarakatnya adalah Kejawen.

Pedoman hidup yang sudah lazim dikenal oleh masyarakat Jawa adalah: aja dumeh (jangan merasa tinggi hati) dan aja aji mumpung (jangan memanfaatkan kesempatan). Perbuatan aja dumeh dan aja aji mumpung merupakan pedoman untuk selalu mawas diri bagi seseorang yang berada di atas angin dan diberi karunia oleh Tuhan Yang Maha Esa. Manusia dalam pandangan Jawa akan mencapai kebahagiaan ketika memenuhi tiga syarat hidup; (1) wirya (berusaha bekerja untuk mencapai kedudukan yang layak sesuai dengan kemampuan dan prestasi kerja yang membawa penghasilan sumber hidup). (2) harta (berusaha mendapatkan modal uang yang halal dari sedikit demi sedikit agar dapat berdagang atau bertukang dan lain sebagainya). (3) wasis (berusaha mendapatkan pengetahuan dan keterampilan baik kasar maupun halus yang membawa sumber kehidupan).

Selain prinsip hidup, masyarakat Jawa juga menjunjung tinggi unggah-ungguh dalam berperilaku dan bertutur. Terdapat tiga bentuk utama variasi, yaitu ngoko ("kasar"), madya ("biasa"), dan krama ("halus"). Di antara masing-masing bentuk ini terdapat bentuk "penghormatan" (ngajengake, honorific) dan "perendahan" (ngasorake, humilific). Seseorang dapat berubah-ubah registernya pada suatu saat tergantung status yang bersangkutan dan lawan bicara. Status bisa ditentukan oleh usia, posisi sosial, atau hal-hal lain. Seorang anak yang bercakap-cakap dengan sebayanya akan berbicara dengan varian ngoko, namun ketika bercakap dengan orang tuanya akan menggunakan krama andhap dan krama inggil.

\section{Perubahan Bahasa dan Budaya Jawa di Yogyakarta}

Pertukaran dan penyerapan budaya luar ke Indonesia mempengaruhi eksistensi budaya asli Indonesia. Di Yogyakarta, kota dengan mobilitas yang tinggi menyebabkan terjadinya percampuran bahasa dan budaya Jawa. Sehingga, masyarakat mencampurcampurkan budaya yang ada. Saat ini sering kita dengar istilah "wong Jawa ilang Jawane", istilah tersebut disematkan kepada masyarakat Jawa yang tidak lagi mengenal atau menggunakan budaya Jawa.

Yogyakarta sebagai kota pelajar sangat memperhatikan kualitas pendidikan yang menjadi pendukung tenaga kerja yang berualitas. Hal tersebut menyebabkan banyak pelajar dari berbagai penjuru wilayah menetap di Yogyakarta sehingga hampir seluruh 
masyarakat Yogyakarta menjadi multilingual. Masyarakat Yogyakarta menguasai bahasa Jawa dan Indonesia, mereka juga menguasai bahasa Inggris sebagai alat komunikasi di era globalisasi.

Kemampuan masyarakat untuk menguasai berbagai bahasa di Yogyakarta mampu menggeser bahasa dan budaya Jawa yang merupakan jati diri Yogyakarta. Di Yogyakarta, masyarakat multilingual disebabkan oleh:

\section{Penjajahan}

Indonesia dijajah Belanda pada tahun 1596 sampai 1942. Dalam kurun waktu yang hampir tiga setentah abab, pasti terdapat pertukaran budaya dan penyerapan bahasa sehingga membuat masyarakat indonesia menjadi multilingual. Beberapa kata yang merupakan serapan dari bahasa Belanda adalah prosekot, sopir, dan kewek. Kata-kata tersebut mengalami perubahan morfologi dari bahasa asli yang kemudian mengalami penyesuaian dengan pelafalan (lexical diffusion) oleh penduduk lokal.

2. Migrasi

Perpindahan penduduk dari dalam ke luar negeri atau sebaliknya sangat berpengaruh pada penguasaan bahasa yang dimiliki oleh seseorang. Perpindahan tersebut bisa karena faktor pekerjaan, pendidikan ataupun perkawinan campuran. Bersamaan dengan perpindahan penduduk, maka mereka juga membawa bahasa dan kebudayaan asal ke tempat tujuan sehingga menggeser bahasa yang telah ada sebelumnya. Di Yogyakarta, terdapat kampung pecinan yang merupakan bukti dari perpindahan penduduk Cina ke Yogyakarta. Selain membawa bahasa mereka juga melestarikan budaya mereka di sini. Sebagai contoh kata serapan dari bahasa Cina adalah Cap Cay yang mengalami perubahan morfologi sehinggan dilafalkan capjae oleh masyarakat Yogyakarta.

3. Internationalisasi

Pertukaran pelajar dan kebudyaan juga berpengaruh besar terhadap keterlangsungan budaya Jawa. Kemampuan barbahasa Inggris sebagai syarat komunikasi dalam dunia global telah merubah pandangan bahwa seseorang yang mampu berkomunikasi dengan bahasa Inggris maka dia mempunyai tingkat intelektual yang tinggi. Sehingga hampir semua masyarakat Yogyakarta menyekolahkan anak-anaknya ke sekolah internasional. Bahkan mereka tidak diajari bahasa Jawa sehingga kemampuan berbahasa Jawa mereka kurang. Istilah yang mengalami perubahan dari bahasa Inggris ke bahasa Jawa musalnya ngeprint, ngapload, face bookan dan lain sebagainya. Istilah-istilah tersebut mengalami perubahan kosa kata; kata-kata dari bahasa Inggris mendapat imbuhan bahasa Jawa.

Seiring perkembangan zaman, bahasa Jawa pun mengalami peubahan. Perubahan tersebut diantaranya:

1. Perubahan Fonologi

Bahasa Jawa mengalami perubahan fonologi dari Aksara Jawa menjadi huruh alfabet. Selain itu, ejaan-ejaan yang digunakan juga berubah sesuai dengan EYD yang ditetapkan dalam bahasa Indonesia. Contoh perubahan fonologi bahasa Jawa:
/j/ (lija) /y/ (liya)
/nj/(njai) /ny/ (nyai)
/oe/ koemat /u/ (kumat)
/sj/(sjarat) /sy/ (syarat)
/tj/ (tjitra) /c/ (citra)
/dj/ (djati) /j/ (jati) 
Selain itu terdapat huruf serapan dari bahasa lain yang diserap ke dalam Bahasa Jawa, yaitu huruf /z/, /f/, /v/. Oarng jawa tidak mempunyai huruf tersebut dalam aksara Jawa dan dalam perkembangannya dibuatlah aksara Jwa utuk menuliskan huruf tersebut.

2. Perubahan morfologi

Berkembanganya teknologi membuat perubahan besar dalam bahasa Jawa. Misalkan dalam komputer, bahasa Jawa belum mempunyai istilah dalam bidang tersebut sehingga menyerap dari bahasa aslinya. Contohnya kata /clik/ bahasa Jawa mengadopsi kata tersebut dan dalam pernggunaannya orang menambahkan awalan /nge-/ sebagai kata kerja /ngeklik/. Kata lain yang mengalami perubahan sejenis adala: /ng-up load/, /n-down load/, nge-print/ dan lain sebagainya.

3. Perubahan sintaksis

Penyingkatan-penyingkatan kata dalam bahasa Jawa merupakan suatu bentuk perubahasn sintaksis. Pada kalimat berikut: ora duwe duwit we kemudian dalam pengucapannya mengalami penyingkatan menjadi ra nde dit te. Penyingkatan tersebut tentunya tidak sesuai dengan kaidah bahasa Jawa dan tentu saja akan sulit dimengerti oleh pendengar.

4. Perubahan kosa kata

Perubahan kosa kata dalam bahasa Jawa merupakan peristiwa terserapnya unsur bahasa lain ke dalam bahasa Jawa. Misalnya kata sopir yang diadopsi dari bahasa Belanda. Selain itu terdapat satu jembatan di Yogyakarta yang merupakan peninggalan Belanda yang namanya diambil dari bahasa Belanda, kretek kewek, namun di Yogyakarta nama tersebut disesuaikan dengan pengucapan bahasa Jawa.

5. Perubahan Semantik

Bahasa Jawa juga mengalami perubahan semantik dalam perkembangannya. Diantara perubahan semantik yang terjadi antara lain: kata /ibu/ yang padazaman dahului berarti orang yang melahirkan kita dan sebutan tersebut hanya boleh digunakan pada ratu, sedangkan sekarang setiap wanita dewasa disebut /ibu/. Kata berikutnya adalah /mas/ pada zaman dahulu setiap orang, pria maupun wanita, yang mempunyai status sosial yang tinggi dipenggil dengan /mas/, dan sekarang kata /mas/ hanya digunakan pada laki-laki dewasa.

Karena bahasa dan budaya merupakan satu-kesatuan yang tidak dapat dipisahkan, maka ketika suatu bahasa mengalami pergeseran hal serupa juga terjadi pada budayanya. Budaya Jawa di Yogyakarta telah bergeser dalam penggunaanya dalam kehidupan seharihari. Berikut beberapa pergeseran budaya yang terjadi:

1. Bahasa Jawa merupakan bahasa yang yang digunakan dalam opercakapan sehari-hari. Bahasa Jawa juga menjunjung tinggi unggah-ungguh dalam bertutur. Saat ini, unggah-ungguh tersebut yang tidak lagi digunakan oleh masyarakat Yogyakarta. Masyarakat Yogyakarta, generasi muda khususnya sulit membedakan antara ngoko ("kasar"), madya ("biasa"), dan krama ("halus"). Hampir seluruh percakapan didominasi dengan bahasa ngoko. Secara tidak langsung, sistem kasta juga berubah, karena seharusnya hanya masyarakat dengan strata sosial yang tinggi yang boleh menggunakan bahasa ngoko. Begitu juga sebaliknya, masyarakat dengan kasta sosial yang rendah harus berbicara menggunakan bahasa krama sebagai penghormatan. 
2. Masyarakat Yogyakarta telah kehilangan jati diri seiring ditinggalkannya pedoman hidup aja dumeh dan aja aji mumpung. Dari pedoman hidup tersebut dapat kita lihat bahwa orang jawa pada dasarnya tidak sombong dan jujur. Namun karena pengaruh budaya yang terjasi dalam kehidupan sehari-hari, hal tersebut kian lama menjadi luntur.

3. Syarat hidup manusia untuk mencapai kebahagiaan; wirya, harta dan wasis juga telah ditinggalkan masyarakat Yogyakarta saat ini. Manusia lebih mengukur kebahagiaan dengan harta yang dimiliki. Jika seseorang memiliki harta yang melimpah pasti hidupnya bahagia. Pikiran seperti itu yang menyebabkan maraknya kasus kriminal seperti perampokan, perjudian dan lain sebagainya. Jika kita tengok dalam syarat mencapai kebahagiaan, memang terdapat harta namun cara pemerolehannya dengan cara yang halal dan kemudian dijadikan sebagai modal usaha. Beberapa tahun lalu, marak pedoman hidup yang dipopulerkan oleh suatu organisasi, yaitu muda foyafoya, tua kaya raya, mati masuk surga. Hal itu jelas bertentangan dengan budaya Jawa yang dikenal sebagai pekerja keras dan tekun.

\section{Kesimpulan}

Perubahan bahasa dan budaya di Yogyakarta terjadi oleh beberapa faktor, yaitu penjajahan, migrasi dan internasionalisasi. Ketiga faktor tersebut merupakan awal dari tumbuhnya masyarakat multilingual yang akhirnya ikut andil dalam perubahan bahasa dan budaya di Yogyakarta. Bahasa jawa dalam perkembangan dunia, mengalami perubahan, yaitu perubahan fonologi, perubahan morfologi, perubahan semantik, perubahan suku kata, perubahan sintaksis. Kekayaan Bahasa dan budaya Indonesia harus selalu kita jaga kelestariaanya. Pertukaran budaya memang dapat memperkaya budaya namun kita perlu saringan agar budaya serapan tersebut tidak merusak budaya yang merupakan jati diri kita. Jika hal ini tidak kita pikirkan muali sekarang, tidak menutup kemungkinan bahasa Jawa akan punah bersama budaya dan pandangan hidupnya.

\section{DAFTAR PUSTAKA}

Chaer, Abdul. 1994. Linguistik Umum. Jakarta: Rineka Cipta. 2004. Sosiolinguistik perkenalan awal. Jakarta: Rineka Cipta.

Holmes, Janet. 1995. An Introduction to Sociolinguistics. London and New York: Longman.

Nababan, PWJ. 1991. Sosiolinguistik: Suatu Pengantar. Jakarta:PT Gramedia.

Narimo, Sabar. 2009. Karakteristik Psiko-Sosio Kultural Manusia dalam Serat WulangReh Karya Pakoe Boewono IV (Tinjauan Pendidikan Informal Masyarakat Jawa. Yogyakarta

Spolsky, Bernard and Hult, Francis. 2008. The Handbook of Educational Linguistics. Oxford: Blackwell Publisher.

Sumarsono dan Partana, Paina.2002.Sosiolinguistik.Yogyakarta:Sabda.

Wardhaugh, Ronald. 2000. An Introduction to Sociolinguistics. Massachusetts: Blackwell Publishers 